\title{
Cold Mass Integration of the ATLAS Barrel Toroid Magnets at CERN
}

Jean-Michel Rey, Michel Arnaud, Christophe Berriaud, Romain Berthier, Sandrine Cazaux, Alexey Dudarev, Michel Humeau, René Leboeuf, Jean-Paul Gourdin, Christophe Mayri, Chhon Pes, Herman ten Kate, and Pierre Védrine

\begin{abstract}
The ATLAS Barrel Toroid, part of the ATLAS Detector built at CERN, is comprised of 8 coils symmetrically placed around the LHC beam axis. The coil dimensions are $25 \mathrm{~m}$ length, $5 \mathrm{~m}$ width and $0.4 \mathrm{~m}$ thickness. Each coil cold mass consists of 2 double pancakes of aluminum stabilized NbTi conductor held in an aluminum alloy casing. Because the magnet is conduction cooled a good bonding between the superconducting winding and the coil casing is a basic requirement. Due to the high load level induced by the Lorentz forces on the double pancakes, a pre-stressing technique has been developed for the assembling of the double pancake windings in the coil casing. This prestressing technique uses inflatable bladders made of extruded aluminum tubes filled with glass microballs and epoxy resin then cured under pressure.

The paper describes the design of the system as well as the problems occurred during the assembling of the 8 superconducting ATLAS coils and the ATLAS BO prototype coil, and the behavior of the Barrel Toroid coils with respect to this prestress during the cold tests.
\end{abstract}

Index Terms-Magnet, pressure effects, superconducting coils.

\section{INTRODUCTION}

$\mathbf{T}$ HE BARREL Toroid Magnet is part of the Magnet System of the ATLAS Detector for the LHC [1], [2]. It consists of eight flat superconducting coils extending over a length of 26 meters with an inner bore of 9 meters and an outer diameter of 20 meters and producing a toroidal magnetic field. The B0 coil [3], [4] which is a shortened racetrack coil, having a length of only 9 meters is a technological prototype using all the previous $R \& D$ efforts to manufacture it. In order to ensure the reliability of the magnet an innovative process for the pre-stressing of the windings in the coil casing has been developed at DAPNIA/ STCM Saclay [5]. This process is described as well as the result of its use during the manufacturing of the B0 prototype and the 8 barrel toroid coils.

At an early stage of the magnet design mechanical calculations showed that the shear stress appearing between the impregnated superconducting winding and its aluminum supporting structure (named "coil casing") were far above the shear limit of the epoxy resin. This stress configuration has been considered as very unsafe for a conduction cooled magnet storing

Manuscript received September 19, 2005. This work is part of the ATLAS Detector Program on the LHC and was supported by the ATLAS Collaboration.

J.-M. Rey, M. Arnaud, C. Berriaud, R. Berthier, S. Cazaux, M. Humeau, R. Leboeuf, C. Mayri, C. Pes, and P. Védrine are with the CEA Saclay-DSM/ DAPNIA, 91191 Gif sur Yvette, France (e-mail: jmrey@dapnia.cea.fr).

A. Dudarev and $\mathrm{H}$. ten Kate are with ATLAS Magnet Team at CERN, CH 1211, Geneva 23, Switzerland.

Digital Object Identifier 10.1109/TASC.2006.870838 high energy. It led to the development of the pre-stressing technique using high pressure epoxy filled inflatable aluminum tubes named "bladders".

Although the process consists mainly in putting strain in one part of the structure, the expression "pre-stressing", being more usual, will be used in the article.

\section{PRe-StRessing CONCEPT}

Each cold mass coil consists of two double pancakes of insulated conductors in a coil casing. The conductor is a pure aluminum stabilized cable obtained by a co extrusion process. After winding the double pancakes are insulated with epoxy resin using a vacuum impregnation technique. As the conductor carries a 20500 A current, each double pancake takes $2.4610^{6}$ amp-turns in a magnetic field gradient of $4.85 \mathrm{~T}$. The Lorentz forces appearing on the winding compress it as the magnet is energized. The indirect cooling technique requires a good bonding of the double pancake and the coil casing.

Avoiding shear stress at the double pancake/coil casing interface is possible if the central part of the coil casing is put in tension during assembling. Then as the magnet is energized, the tension in the coil casing is released by the magnetic compression of the double pancake, but shear stress does not appear at the interface.

The technique used to create the pre-stress is to use inflatable bladders on each side of the superconducting winding. Some of them are bent to be placed in the corners of the pancake windings. The bladders are filled with micro balls of glass and impregnated with liquid epoxy resin, then pressurized and cured under pressure. Once filled with liquid resin and pressurized the bladders act as hydraulic jacks, putting the double pancake coils in compression and the coil casing in tension. After curing the epoxy resin under pressure the bladders work like compressed shims due to the tensile strain stored in the coil casing. Fig. 1 shows a section of the cold mass with the magnetic fields and compressive stress values appearing on the winding due to the field and to the bladders.

\section{INTEGRATION PROCESS}

Major parts have been subcontracted in the European industry and shipped to CERN for assembling [6].

One of the critical problems in the assembly scenario was the handling of the $25 \mathrm{~m} \times 5 \mathrm{~m}$ double pancake winding, each of them weighting $7500 \mathrm{~kg}$ with a bending displacement lower than $2 \mathrm{~mm} / \mathrm{m}$ over the coil length. To solve this problem the handling operations have been made using the coil casing as part of the lifting equipment. 

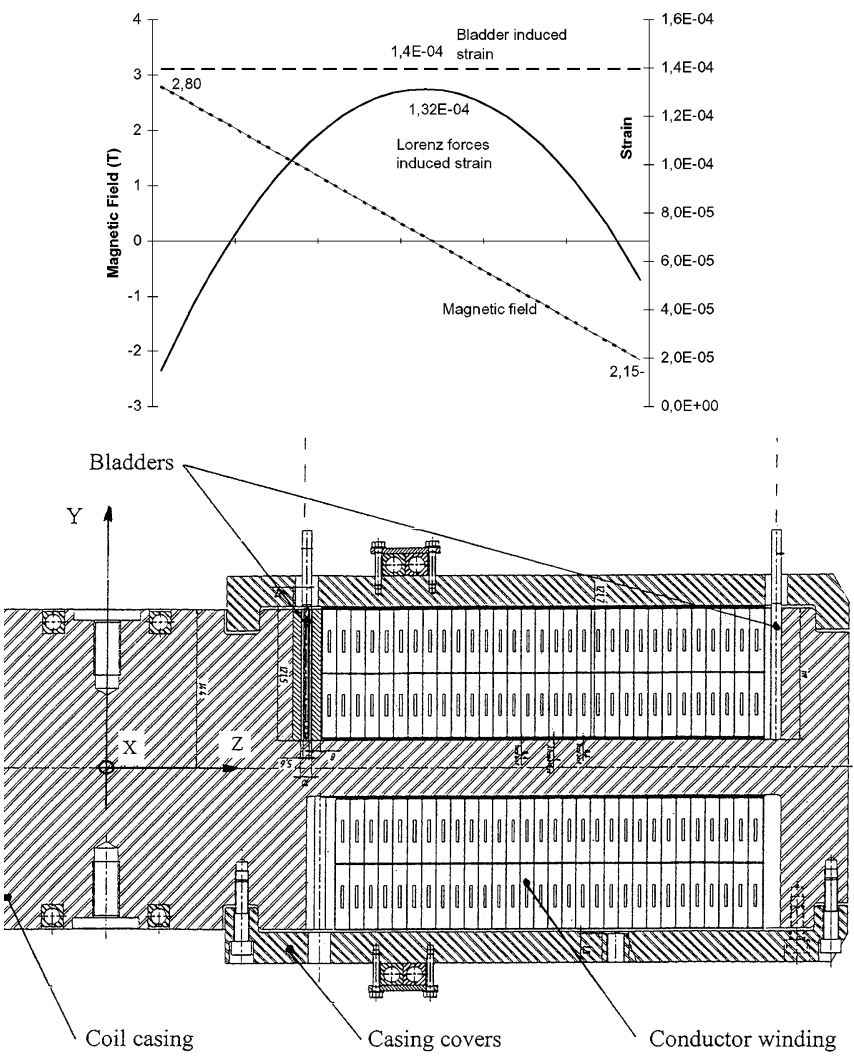

Fig. 1. Upper part: magnetic field and its induced strain and bladder induced strain as a function of the conductor location along the coil casing width (along $\mathrm{X}$ axis). Lower part: cross section of the ATLAS race-track coil. The bladders are located on each side of the conductor windings. The bladders of the lower winding are not represented.

The assembling scenario follows this sequence:

- The double pancake windings are covered with glass fiber cloth pre-impregnated with slow reactivity epoxy resin (pre-preg).

- The coil casing is put in place over one double pancake, and both parts are provisionally clamped together.

- The provisional assembling is turned over.

— The bladders and shims are inserted between the coil casing and the double pancakes.

- A complementary pre-preg layer is put in place on the double pancake winding.

- The casing covers are put in place over the double pancake.

- The operations are repeated for the second double pancake.

The pre-stressing operations can start at this point.

Fig. 2 illustrates the turn over operations.

\section{Pre-Stressing Process}

Several years of R\&D activity [5], [7] have been necessary to optimize the process and qualify the filling materials for the bladders. The efficiency of the bladder has been defined as the ratio of the measured force applied by the bladder to the calculated force applied by an hydraulic jack having the same external section as the bladder. This has been measured and is $83 \%$. A $500 \mathrm{~mm}$ long full section mock up has been realized to control the elongation of the coil casing during the integration process. It allowed a test of the complete pre-stressing sequence,

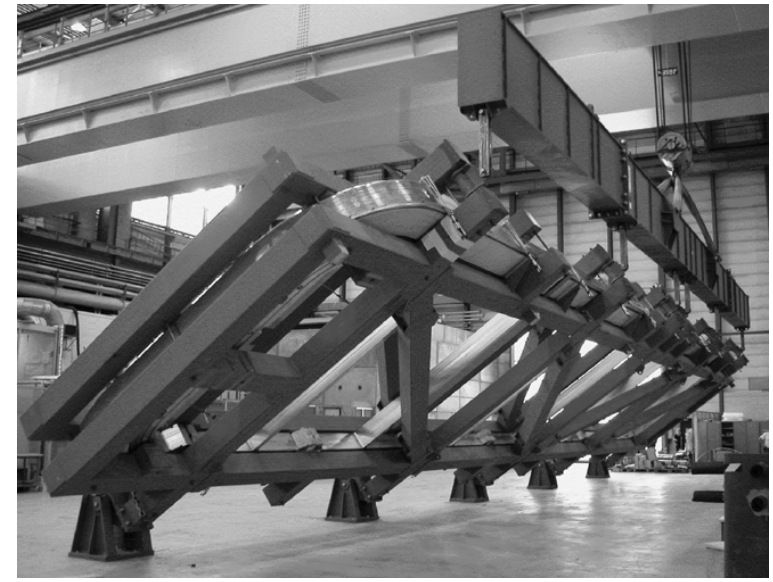

Fig. 2. A cold mass comprising one coil casing and two double pancake windings during a turn over operation.

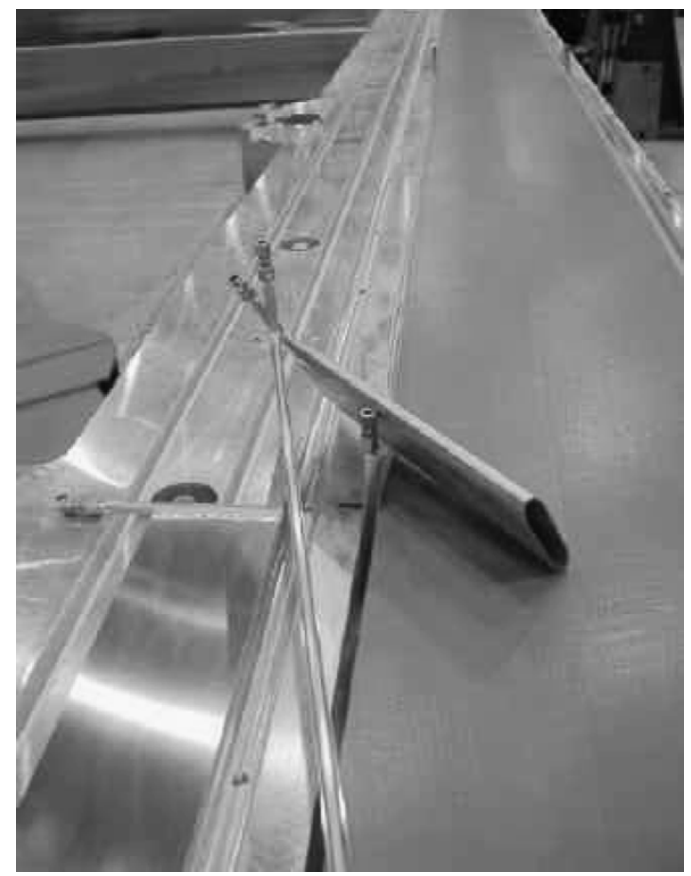

Fig. 3. View of a bladders on top of a double pancake inserted in the coil casing. The cut bladder has been inflated and is already 3 times thicker than before inflation. One bladder is already inserted in the gap between the coil casing and the double pancake winding.

the qualification of the hydraulic jacks for the resin injection, and a measurement of the coil casing elongation.

The pre-stress sequence is the following:

- The bladders are inflated with gaseous nitrogen to 20 bars (2 MPa) to expand and fill the gap between the double pancake and the coil casing.

- The gaseous nitrogen is released and the bladders are filled with glass micro balls having a diameter between $0.45 \mathrm{~mm}$ and $0.85 \mathrm{~mm}$.

— Once filled the bladders are provisionally sealed.

The assembly process continues until the previous operations are completed on both double pancakes for one coil casing. 
TABLE I

BLAdDER MANUfacturing CHANGES From B0 AND BT

\begin{tabular}{lcc}
\hline \hline & B0 & BT \\
\hline Material & $5754 \mathrm{H} \mathrm{111}$ & EN AW-3003 F 10 \\
Processing & Flattened tubes & Extruded flat tubes \\
Wall thickness & $1.15 \mathrm{~mm}$ & $1.6 \mathrm{~mm}$ \\
Shape & Constant thickness & Local reinforcement \\
Number used & 48 & 848 \\
\hline \hline
\end{tabular}

— The complete injection tubing is assembled to link the 106 bladders for one cold mass (altogether 846 high pressure unions per coil).

- The thermal protection is put in place to allow the curing of the epoxy resin.

- The cover pressing system is installed. It comprises load plates and rubber bladders linked together and inflated with Nitrogen to 5 bars $(0.5 \mathrm{MPa})$.

The pre-stressing sequence can then start:

- The remaining gas is evacuated from the bladder at a pressure of 5 mbars.

- The bladder is impregnated with epoxy resin. The pressure applied on the resin is increased to $2 \mathrm{MPa}$ for two hours in order to impregnate completely the micro balls in the bladder.

- The pressure is then increased to $12 \mathrm{MPa}$ by steps of $2 \mathrm{MPa}$. The tubing and the connections are checked at each step to prevent leakages.

- The system is cured under pressure.

Pressurizing of the liquid resin has been achieved using a high pressure oil pump to pressurize twinned resin jacks. The high pressure oil is injected in one jack that pushes on a second coaxial jack filled with epoxy resin. In order to cure the magnet once under pressure the winding is powered to generate Joule heating. The current, up to $430 \mathrm{~A}$, goes in the high purity aluminum stabilizer, allowing a maximum temperature of $125^{\circ} \mathrm{C}$ for the full hardening of the epoxy resin.

\section{THE B0 EXPERIENCE}

Despite the efforts made to achieve a safe process for the B0 prototype, several leaks occurred from the bladders during the integration. There is no way back to dismantle the magnet once the epoxy resin is injected in the bladders and the magnet was cured. The bladder manufacturing technique was reanalyzed afterwards to improve the operational safety. The changes are summarized in Table I. Nevertheless the mean elongation measured on the B0 coil casing at the places where the bladders had not been leaking was greater than the specified value of $0.2 \mathrm{~mm}$. Table II gives the elongation of the coil casing as measured in the location with good and leaking bladders. The conclusions reached at that time were that even with leaking bladders an elongation is induced in the structure. It is shown in Table II that $0.13 \mathrm{~mm}$ is the mean value of elongation at the location of the 3 leaking bladders. This fact has been attributed to the compaction of the glass micro balls under the effect of gravity that does not allow the bladder to flatten again once put under pressure.
TABLE II

CoIl CASing Elongation Measured in B0 AND BT

\begin{tabular}{lccc}
\hline \hline & $\begin{array}{c}\text { Number of } \\
\text { sections }\end{array}$ & $\begin{array}{c}\text { Mean } \\
\text { elongation }\end{array}$ & Standard deviation \\
\hline $\begin{array}{l}\text { B0 working } \\
\text { section }\end{array}$ & 4 & 0.27 & 0.05 \\
$\begin{array}{l}\text { B0 leaking } \\
\text { section }\end{array}$ & 3 & 0.13 & 0.06 \\
B1 & & & \\
B2 & 26 & 0.178 & 0.088 \\
B3 & 25 & 0.126 & 0.052 \\
B4 & 26 & 0.28 & 0.107 \\
B5 & 26 & 0.192 & 0.053 \\
B6 & 26 & 0.222 & 0.037 \\
B7 & 26 & & \\
B8 & 26 & 0.101 & 0.026 \\
\hline \hline
\end{tabular}

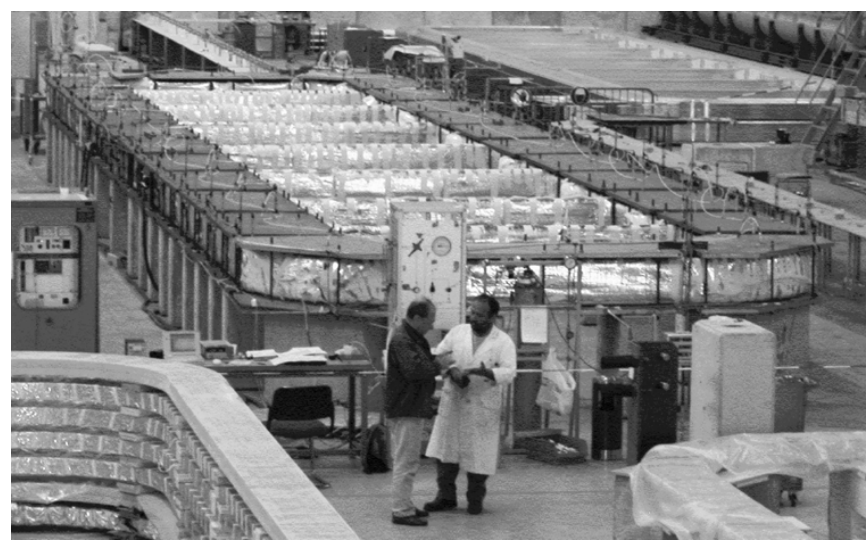

Fig. 4. A completely assembled cold mass during the curing under pre-stress operation.

The tests of the B0 magnet were done during the winter 2000 and proved to be very successful [8], the 40 ton magnet suffered altogether around 40 deliberately induced quenches without significant degradation proving the efficiency of its design.

\section{THE BT EXPERIENCE}

The integration of the 8 cold masses for the ATLAS Barrel Toroid took place during the year 2003. The pre-stressing operations went fine, only one among the total of 848 bladders leaked at 50 bars.

The measured values of the coil casing elongation are given in Table II. In the case of BT the mean elongation represents the mean value of 21 points of measure. The pre-stressing of the 8 coils winding is homogeneous although the measurement of the elongation shows a fairly large scatter between the different coils. As at least 3 weeks took place between the initial (before pre-stressing) and final (after curing of the coil) width measurements the temperature change is the most probable explanation of this scatter. A specific tool to perform the measurement has been developed but it has been available only for coil 4 and later. Nevertheless the precision is better, the standard deviation being less than $30 \%$ of the mean elongation measured. The elongation of coil 6 was not determined because the measurement of the coil width before pre-stressing had been forgotten. 
On $\mathrm{B} 0$ the coil casing was a thick monolithic aluminum piece made of plates welded by electron beam welding. This was a critical process and has been replaced on BT by a bolted assembling of thinner plates assembled using TIG welding. The change of manufacturing technique can also explain the lower elongation of the BT coil casing compared to B0.

A result of the technique developed was that the bladders being inflated in place were able to withstand fairly large dimensional changes from one impregnated double pancake to the other. No other mechanical device would have allowed matching the size and shape dispersion of the impregnated winding as easily as the inflatable bladder technique.

The tests of the 8 magnets confirmed the efficiency of the process, no one of them showed training [9]-[11].

\section{CONCLUSION}

An innovative and original process has been used for the assembling of the cold masses of the ATLAS Barrel Toroid. It uses inflatable aluminum bladders filled with glass micro balls and epoxy resin pressurized at 120 bars during curing. The problems arising during the integration of the B0 prototype have been solved for the Barrel Toroid coils.

The developed technique allows matching the dimensional changes of the impregnated windings and therefore does not need precise machining on large pieces. Even in the case of leaks appearing in one of the bladders a pre-stress was generated in the structure. With only one bladder leaking over 848 pressurized during the integration process of the 8 ATLAS Barrel Toroid coils the technique developed is considered safe efficient and reliable.

\section{ACKNOWLEDGMENT}

The authors express their warm thanks to all the staff members of JINR, Technicatome, CERN and DAPNIA having cured the 8 coils during long overnight shifts.

\section{REFERENCES}

[1] A. Daël et al., "Progress in the design of the barrel toroid magnet for the ATLAS experiment and associated R\&D at CEA-Saclay and INFNMilano," Proc. 15th Int. Conf. Magnet Technology Science press, pp. 92-95, 1998.

[2] H. H. J. ten Kate, "ATLAS superconducting toroids and solenoid," IEEE Trans. Appl. Supercond., vol. 15, no. 2, pp. 1267-1270, 2005

[3] A. Dael et al., "Construction of the ATLAS B0 model coil," IEEE Trans. Appl. Supercond., vol. 11, no. 1, pp. 1597-1600, Mar. 2001.

[4] _ _ "Synthesis of the technological developments for the B0 model coil and the ATLAS barrel toroid coils," IEEE Trans. Appl. Supercond., vol. 10, no. 1, pp. 361-364, Mar. 2000.

[5] J. M. Rey et al., "Prestressing concepts and related materials qualifications for the ATLAS barrel toroid coil," Adv. Cryogenic Eng. Mater., vol. 46, pp. 65-72, 2000.

[6] P. Vedrine et al., "Manufacturing and integration progress of the ATLAS barrel toroid air core magnet at CERN," IEEE Trans. Appl. Supercond., vol. 14, no. 2, pp. 491-494, Jun. 2004.

[7] J. M. Rey et al., "Epoxy resin developments for the ATLAS and CMS superconducting magnets impregnation," Adv. Cryogenic Eng. Mater., vol. 42, pp. 37-42, 1996.

[8] N. Dolgetta et al., "Review of the ATLAS B0 model coil test program," IEEE Trans. Appl. Supercond., vol. 14, no. 2, pp. 495-504, 2004.

[9] A. Dudarev et al., "First full size ATLAS barrel toroid coil successfully tested," presented at the Applied Superconductivity Conf., Jacksonville, USA, Oct. 2004.

[10] C. Berriaud et al., "On-surface test of the ATLAS barrel toroid coils: acceptance criteria and results," in this conference.

[11] A. Dudarev et al., "On-surface test of the ATLAS barrel toroid coils: overview," in this conference. 